\title{
Antenatal and postnatal depression: A public health perspective
}

Saurabh R. Shrivastava, Prateek S. Shrivastava, Jegadeesh Ramasamy

Department of Community Medicine, Shri Sathya Sai Medical College and Research Institute, Chennai, Tamil Nadu, India

\section{ABSTRACT}

Depression is widely prevalent among women in the child-bearing age, especially during the antenatal and postnatal period. Globally, post-partum depression has been reported in almost $10 \%$ to $20 \%$ of mothers, and it can start from the moment of birth, or may result from depression evolving continuously since pregnancy. The presence of depression among women has gained a lot of attention not only because of the rising incidence or worldwide distribution, but also because of the serious negative impact on personal, family and child developmental outcomes. Realizing the importance of maternal depression on different aspects-personal, child, and familial life, there is a crucial need to design a comprehensive public health policy (including a mental health strategy), to ensure that universal psychosocial assessment in perinatal women is undertaken within the primary health care system. To conclude, depression during pregnancy and in the postnatal period is a serious public health issue, which essentially requires continuous health sector support to eventually benefit not only the woman, but also the family, the community, and health care professionals.

Key words: Family, healthcare professionals, postpartum depression, pregnancy

\section{Introduction}

Antenatal care relates to the care of women during pregnancy with an ultimate target to achieve a healthy mother and a healthy child at the end of pregnancy. ${ }^{[1]}$ However, antenatal care encompasses not only clinical examinations/laboratory investigations but also the mental conditioning of the women before arrival of the child. ${ }^{[1]}$ In fact, adequate time and opportunity should be given to pregnant women to clear all the fears, myths, and misconceptions associated with pregnancy or delivery. ${ }^{[2]}$ Worldwide, depression has been acknowledged as one of the major public health problems that is almost twice as common in women during the childbearing age than in men, and is expected to become the second most prevalent of all general health problems globally by the year 2020.[2,3]

\begin{tabular}{|l|l|}
\hline \multicolumn{2}{|c|}{ Access this article online } \\
\hline Quick Response Code: & Website: \\
\hline & www.ruralneuropractice.com \\
\cline { 2 - 3 } & \\
\hline & \\
\hline
\end{tabular}

Depression during pregnancy and in postpartum period Depression is widely prevalent among women in the child-bearing age, especially during the antenatal and postnatal period. ${ }^{[4]} \mathrm{In}$ fact, different studies done across variable settings have reflected presence of antenatal and postnatal depression among both women and their husbands. ${ }^{[3,5]}$ However, these estimates do not reveal the exact picture, as most of the cases remain undiagnosed/unreported due to the absence of international agreement on screening. ${ }^{[3]}$ This depression deserves more attention as this period is a time of intense change (viz. physiologically/appearance-wise/socially/ mentally) and transition for women, that essentially necessitates adaptation and family support. ${ }^{[3]}$ Generally, the postpartum period is a time for the occurrence of anxious and depressive events (viz. fatigue, anxiety, disordered sleeping, changing mood, irritability, feelings of loss and sadness, and sometimes even loss of self-esteem).$^{[5,6]}$ Globally, post-partum depression has been reported in almost $10 \%$ to $20 \%$ of mothers, and it can start from the moment of birth, or may result from depression evolving continuously since pregnancy. ${ }^{[5,7]}$ Thus, screening of pregnant females has been recommended using different predictive tools to facilitate early detection of depression. ${ }^{[5,7]}$ However,

Address for correspondence:

Dr. Saurabh R. Shrivastava, Department of Community Medicine, $3^{\text {rd }}$ floor, Shri Sathya Sai Medical College and Research Institute, Ammapettai Village, Thiruporur - Guduvancherry Main Road, P.O. Sembakkam, Kancheepuram - 603 108, Tamil Nadu, India. E-mail: drshrishri2008@gmail.com 
while planning corrective strategies there is a need to develop strategies based on the local settings (viz. in developing countries, most of the deliveries are conducted at home without much antenatal care, while in developed nations where antenatal checkup and care is the routine norm).

\section{Potential risk factors}

A wide range of potential risk factors ranging from socio-demographic parameters, family dynamics, antenatal determinants, medical illness and pregnancy related outcomes, and health sector related attributes have been attributed to the causation of depression among women as mentioned in Table $1 .{ }^{[6,8-14]}$ Similarly, parameters such as suicidal ideation among mothers, ${ }^{[15,16]}$ unemployment status; ${ }^{[9]}$ fewer biological children; poor marital relationship quality; ${ }^{[10,11]}$ first-time parenting; ${ }^{[9]}$ lack of awareness about postnatal depression; ${ }^{[12]}$ lack of social support or a limited circle of friends; ${ }^{[11]}$ and concurrent stressful life events, ${ }^{[13]}$ have been identified in precipitating depression among husbands.

On analysis of all the determinants, the most important contributor in causation of antenatal/postnatal depression is because of the absence of family support. Presence of a healthy and supportive family environment, especially support from the husband can virtually neutralize all the triggering factors. However, the share of inefficient health care delivery system is also extremely crucial especially in low-resource settings.

\section{Consequences of depression}

The presence of depression among women has gained a lot of attention not only because of the rising incidence or worldwide distribution, but also because of the serious negative impact on personal, family and child developmental outcomes. ${ }^{[4]}$ From the child's perspective, parental depression has shown a negative impact on cognition, emotional and physical development of the infant and behavioral disturbances. ${ }^{[5,6]}$ As far as mothers are concerned, onset of depression tends to affect the quality of the relationship with the spouse and on other social relationships; brings about an alteration in the manner in which mother takes care of the baby; negatively influence the quality of life; prevents mother from resuming her job and thus affects the economic productivity of women and family. ${ }^{[5,6,17,18]}$ In fact, depression during antenatal/postnatal period even influences the men in their ways of fathering (viz. feeling that partner's depression led to significant physical and/or psychological maternal absence as well as a fracturing of the family unit). ${ }^{[9,10,19]}$ Furthermore, antenatal depression has also been associated with pre-term onset of labor, risk of preterm birth, low birth weight, and intrauterine growth restriction. ${ }^{[20-22]}$

In fact, findings of a cohort study (viz. Avon Longitudinal Study of Parents and Children) revealed that prenatal depression is an important determinant of the childhood conduct problems, suicidal ideation in the kids, and early onset of adult depression. ${ }^{[15,23]}$ In an another mother-child cohort study impact of maternal antenatal conditions on reproductive outcomes, infant and child neurodevelopment and behavior, child development, and postnatal depression of the mothers, has been explored. ${ }^{[24]}$ Similar sort of impact on child neurodevelopment has been observed in another mother and child cohort study. ${ }^{[25]}$

\section{Recommended measures}

Although multiple gaps have been identified in the existing health set-up/policies, however the most cost-effective and easily implementable intervention will be improving the quality of services offered to an antenatal mother during her pregnancy and in her postnatal period. ${ }^{[1]}$ This does not require any major pooling of resources and can be delivered to the women/ family members without bringing about any major health reform. ${ }^{[1,26]}$

In fact, the physician/attending health care professionals can actively screen mothers/fathers for their stressors,

Table 1: Potential risk factors for causation of antenatal/postnatal depression

\begin{tabular}{|c|c|c|c|c|}
\hline $\begin{array}{l}\text { Socio-demographic } \\
\text { parameters }\end{array}$ & Family dynamics & $\begin{array}{l}\text { Antenatal } \\
\text { determinants }\end{array}$ & $\begin{array}{l}\text { Medical illness and } \\
\text { pregnancy related } \\
\text { outcomes }\end{array}$ & $\begin{array}{l}\text { Health sector related } \\
\text { attributes }\end{array}$ \\
\hline $\begin{array}{l}\text { Age younger than } \\
\text { 18; race or ethnicity; } \\
\text { educational status; } \\
\text { living in a deprived } \\
\text { area; poverty/low } \\
\text { socio-economic } \\
\text { status; and } \\
\text { socio-cultural beliefs }\end{array}$ & $\begin{array}{l}\text { History of marital/domestic violence; } \\
\text { poor relationship with their partner; } \\
\text { negligible support from the husband, } \\
\text { family members, and members } \\
\text { of society; lack of knowledge and } \\
\text { awareness about alteration in mood } \\
\text { and thoughts during pregnancy and } \\
\text { after delivery among women/family } \\
\text { members; and birth of girl child, } \\
\text { when son was desired }\end{array}$ & $\begin{array}{l}\text { Unplanned } \\
\text { pregnancy; myths } \\
\text { and misconceptions } \\
\text { associated with } \\
\text { pregnancy; poor health } \\
\text { during antenatal period; } \\
\text { and poor healthcare } \\
\text { seeking behavior }\end{array}$ & $\begin{array}{l}\text { History of depression; } \\
\text { pre-existing physical } \\
\text { or mental health } \\
\text { problems; peripartum/ } \\
\text { postpartum adverse } \\
\text { outcome (viz. newborn } \\
\text { ill health/still birth); } \\
\text { and poor maternal } \\
\text { postnatal health }\end{array}$ & $\begin{array}{l}\text { Inequity in provision of and } \\
\text { access to health services; } \\
\text { untrained status of the health } \\
\text { professionals; absence of } \\
\text { specific guidelines for the } \\
\text { health professionals; poor } \\
\text { quality of doctor-patient } \\
\text { communication; and absence } \\
\text { of a holistic policy developed } \\
\text { based on the needs of women }\end{array}$ \\
\hline
\end{tabular}


guide them to deal with the stress of pregnancy (viz. ensuring support of family members, medication, removal of triggering factors), and even extend referral services, if needed..$^{[1,6,10,26]}$ Furthermore, it has been recommended that medical practitioners should have a high index of suspicion, and assess the mother for the presence of depression during their health center visits. ${ }^{[1,6]}$ Indirectly, to maximize the output of services in the antenatal period there is a need of sensitizing health care professionals regarding the need to facilitate early detection of depression; ${ }^{[6]}$ addressing communication skills of the physicians, ${ }^{[6]}$ motivating health staffs to understand the familial dynamics; ${ }^{[6]}$ and ensuring involvement of husband during antenatal and postnatal period..$^{[9,18]}$

The next most important intervention can be to design a comprehensive public health policy (including a mental health strategy), to ensure that universal psychosocial assessment in perinatal women is undertaken within the primary health care system. ${ }^{[3,12]}$

In addition, acknowledging the importance of maternal depression on different aspects-personal, child, and familial life, implementation of other interventions such as analysis of women's needs prior to formulation of policies; ${ }^{[12]}$ promoting rationale use of predictive tools during antenatal period to facilitate early detection; ${ }^{[5,7]}$ extending psychosocial and psychological support; ${ }^{[27]}$ promoting adoption of antenatal emotional self-management training programs/group cognitive behavior therapy; ${ }^{[16,28]}$ encouraging women for dietary supplements/exercise; ${ }^{[29,30]}$ and conducting online cognitive behavior training programs for mothers who are reluctant to approach health centers; ${ }^{[31]}$ can also be planned in a strategic manner to counter the problem of depression during antenatal/postnatal period.

\section{Conclusion}

To conclude, depression during pregnancy and in the postnatal period is a serious public health issue, which essentially requires continuous health sector support to eventually benefit not only the woman, but also the family, the community, and health care professionals.

\section{References}

1. Park K. Preventive medicine in obstetrics, paediatrics and geriatrics. In: Park K, editor. Text Book of Preventive and Social Medicine. $20^{\text {th }}$ ed. Jabalpur: Banarsidas Bhanot Publishers; 2009. p. 450-5.

2. World Health Organization. Women's mental health: An evidence based review. WHO press: Geneva; 2000.

3. Glavin K, Leahy-Warren P. Postnatal depression is a public health nursing issue: Perspectives from Norway and Ireland. Nurs Res Pract 2013;2013:813409.

4. Parsons CE, Young KS, Rochat TJ, Kringelbach ML, Stein A. Postnatal depression and its effects on child development: A review of evidence from low- and middle-income countries. Br Med Bull 2012;101:57-79.

5. Teissedre F, Chabrol H. A study of the Edinburgh Postnatal Depression Scale (EPDS) on 859 mothers: Detection of mothers at risk for postpartum depression. Encephale 2004;30:376-81.

6. Babatunde T, Moreno-Leguizamon CJ. Daily and cultural issues of postnatal depression in African women immigrants in South East London: Tips for health professionals. Nurs Res Pract 2012;2012:181640.

7. Eberhard-Gran M, Slinning K, Rognerud M. Screening for postnatal depression-a summary of current knowledge. Tidsskr Nor Laegeforen 2014;134:297-301.

8. Redshaw M, Henderson J. From antenatal to postnatal depression: Associated factors and mitigating influences. J Womens Health (Larchmt) 2013;22:518-25.

9. Khan TM. Interventions during pregnancy to lower the chances of postnatal depression among women from the Asian subcontinent. Ment Health Fam Med 2011;8:7-9.

10. Khan TM, Arif NH, Tahir H, Anwar M. Role of the husband's knowledge and behaviour in postnatal depression: A case study of an immigrant Pakistani woman. Ment Health Fam Med 2009;6:195-201.

11. Zhang Y, Zou S, Cao Y, Zhang Y. Relationship between domestic violence and postnatal depression among pregnant Chinese women. Int J Gynaecol Obstet 2012;116:26-30.

12. Almond P, Lathlean J. Inequity in provision of and access to health visiting postnatal depression services. J Adv Nurs 2011;67:2350-62.

13. Osborn T. Training health visiting support staff to detect likelihood of possible postnatal depression. Community Pract 2012;85:24-7.

14. Jain A, Tyagi P, Kaur P, Puliyel J, Sreenivas V. Association of birth of girls with postnatal depression and exclusive breastfeeding: An observational study. BMJ Open 2014;4:e003545.

15. Geulayov G, Metcalfe C, Heron J, Kidger J, Gunnell D. Parental suicide attempt and offspring self-harm and suicidal thoughts: Results from the avon longitudinal study of parents and children (ALSPAC) birth cohort. J Am Acad Child Adolesc Psychiatry 2014;53:509-17. e2.

16. Tabb KM, Gavin AR, Guo Y, Huang H, Debiec K, Katon W. Views and experiences of suicidal ideation during pregnancy and the postpartum: Findings from interviews with maternal care clinic patients. Women Health 2013;53:519-35.

17. Santos HP Jr, Sandelowski M, Gualda DM. Bad thoughts: Brazilian women's responses to mothering while experiencing postnatal depression. Midwifery 2014;30:788-94.

18. Scope A, Leaviss J, Kaltenthaler E, Parry G, Sutcliffe P, Bradburn M, et al. Is group cognitive behaviour therapy for postnatal depression evidence-based practice? A systematic review. BMC Psychiatry 2013;13:321.

19. Beestin L, Hugh-Jones S, Gough B. The impact of maternal postnatal depression on men and their ways of fathering: An interpretative phenomenological analysis. Psychol Health 2014;29:717-35.

20. Dayan J, Creveuil C, Marks MN, Conroy S, Herlicoviez M, Dreyfus M, et al. Prenatal depression, prenatal anxiety, and spontaneous preterm birth: A prospective cohort study among women with early and regular care. Psychosom Med 2006;68:938-46.

21. Ehsanpour S, Shabangiz A, Bahadoran P, Kheirabadi GR. The association of depression and preterm labor. Iran J Nurs Midwifery Res 2012;17:275-8.

22. Grote NK, Bridge JA, Gavin AR, Melville JL, Iyengar S, Katon WJ. A meta-analysis of depression during pregnancy and the risk of preterm birth, low birth weight, and intrauterine growth restriction. Arch Gen Psychiatry 2010;67:1012-24.

23. Stringaris A, Lewis G, Maughan B. Developmental pathways from childhood conduct problems to early adult depression: Findings from the ALSPAC cohort. Br J Psychiatry 2014;205:17-23.

24. Koutra K, Vassilaki M, Georgiou V, Koutis A, Bitsios P, Chatzi L, et al. Antenatal maternal mental health as determinant of postpartum depression in a population based mother-child cohort (Rhea Study) in Crete, Greece. Soc Psychiatry Psychiatr Epidemiol 2014;49:711-21.

25. Rebagliato M, Murcia M, Alvarez-Pedrerol M, Espada M, Fernández-Somoano A, Lertxundi $\mathrm{N}$, et al. Iodine supplementation during pregnancy and infant neuropsychological development. INMA 
Mother and Child Cohort Study. Am J Epidemiol 2013;177:944-53.

26. Umboh SJ, How $\mathrm{CH}$, Chen $\mathrm{H}$. Postnatal depression: A family medicine perspective. Singapore Med J 2013;54:477-81.

27. O'Hara MW. Psychosocial and psychological interventions reduce the risk of postnatal depression compared with standard care. Evid Based Nurs 2014;17:38-9.

28. Mao HJ, Li HJ, Chiu H, Chan WC, Chen SL. Effectiveness of antenatal emotional self-management training program in prevention of postnatal depression in Chinese women. Perspect Psychiatr Care 2012;48:218-24.

29. Miller BJ, Murray L, Beckmann MM, Kent T, Macfarlane B. Dietary supplements for preventing postnatal depression. Cochrane Database Syst Rev 2013;10:CD009104.
30. Daley AJ, Jolly K, Sharp DJ, Turner KM, Blamey RV, Coleman S, et al. The effectiveness of exercise as a treatment for postnatal depression: Study protocol. BMC Pregnancy Childbirth 2012;12:45.

31. Jones BA, Griffiths KM, Christensen H, Ellwood D, Bennett K, Bennett A. Online cognitive behaviour training for the prevention of postnatal depression in at-risk mothers: A randomised controlled trial protocol. BMC Psychiatry 2013;13:265.

How to cite this article: Shrivastava SR, Shrivastava PS, Ramasamy J. Antenatal and postnatal depression: A public health perspective. J Neurosci Rural Pract 2015;6:116-9.

Source of Support: Nil. Conflict of Interest: None declared. 